Volume 9, No.5, September - October 2020

International Journal of Advanced Trends in Computer Science and Engineering

Available Online at http://www.warse.org/IJATCSE/static/pdf/file/ijatcse168952020.pdf

https://doi.org/10.30534/ijatcse/2020/168952020

\title{
Low Profile ZnO Growth on Si Wafer Using Hydrothermal Method for Sensor Applications
}

\author{
Muhammad Syarifuddin Yahya ${ }^{1}$, Md Rabiul Awal ${ }^{1 *}$, Mohd Zaki Mohd Yusoff ${ }^{2}$, Nurul Alfatihah Mohd \\ Ariffin $^{1}$, Ahmad Nazri Dagang ${ }^{1}$, Muhammad Firdaus Asyraf Abdul Halim Yap ${ }^{3}$ \\ ${ }^{1}$ Faculty of Ocean Engineering Technology and Informatics, Universiti Malaysia Terengganu, 21030 Kuala \\ Nerus, Terengganu, Malaysia, \{syarif_yahya; rabiul.awal; nazri.dagang\} @umt.edu.my, \\ nalfatihah21@gmail.com \\ ${ }^{2}$ Department of Applied Sciences, Universiti Teknologi MARA (UiTM) Cawangan Pulau Pinang, Jalan \\ Permatang Pauh, 13500 Permatang Pauh, Pulau Pinang, Malaysia, zaki7231@uitm.edu.my \\ ${ }^{3}$ Faculty of Innovative Design and Technology, Universiti Sultan Zainal Abidin, 21300 Kuala Nerus, Terengganu, \\ Malaysia, firdausasyraf@unisza.edu.my
}

\begin{abstract}
$\mathrm{ZnO}$ was grown on a silicon wafer $(1 \mathrm{~cm} \times 1 \mathrm{~cm})$ via hydrothermal method in this study. Initially, the zinc oxide colloid solution was spin-coated on the $\mathrm{Si}$ wafer at $400 \mathrm{rpm}$ for $30 \mathrm{~s}$ for the seeding process prior to the $\mathrm{ZnO}$ growth. The presence of $\mathrm{ZnO}$ from the growing process was confirmed with the X-ray diffraction (XRD). The crystallite size was calculated to be $6.34 \mathrm{~nm}$ using Scherer equation. In addition, an energy dispersive X-ray (EDX) characterization was carried out to further verify the presence of the $\mathrm{ZnO}$. Meanwhile, the scanning electron microscopy (SEM) characterization was done to observe the surface morphology of the sample. It is found that the $\mathrm{ZnO}$ structure has a coral-like shape, which is full of asperities and sharp edges. The sample was able to generate a voltage in the range of 180 $\mathrm{mV}$ to $240 \mathrm{mV}$ peak to peak under random pressure.
\end{abstract}

Key words: Zinc Oxide ( $\mathrm{ZnO})$, hydrothermal, growth, surface structure, vibration sensor.

\section{INTRODUCTION}

Zinc oxide $(\mathrm{ZnO})$ is a functional and versatile inorganic material in the II-VI material groups which has been used as early as in ancient Egypt and Rome for adverse skin treatment [1]. In our modern society, it is widely used for paints, as an additive for plastics and rubber as well as a coating material for paper. As for the electronics industry, it is a type of semiconductor with a direct wide bandgap at $3.37 \mathrm{eV}$ (room temperature) and large exciton binding energy $(60 \mathrm{meV})$ [2].

$\mathrm{ZnO}$ nanoparticles have been reported to exist in a number of surface morphologies. For instance, they have existed in many forms like nanoflowers, nanotrees, nanobridges, nanonails and nanotbelts [3, 4]. Furthermore, through Yamada and Tobisawa work, they reported more $\mathrm{ZnO}$ morphology varieties like plates, columns, pyramids, stellar shape crystal, spheres, whiskers and dendrites under the converging shockwave with an explosive charge [5].

$\mathrm{ZnO}$ powder is manufactured industrially by pyrometallurgical or hydrometallurgical processes. Metallurgical methods for the processing of $\mathrm{ZnO}$ by oxidation began in Germany in the 1700s [6]. In the 19th century, three large-scale methods, named the direct method (American process), the indirect method (French process) and the hydrometallurgical system, were created to manufacture $\mathrm{ZnO}$ pigment [6]. Recently, lots of chemical methods like sol-gel [7], hydrothermal, microemulsions, direct precipitation and microwave-assisted synthesis have been used for the $\mathrm{ZnO}$ nanoparticle processing [4, 6]. In addition, other method like radio frequency (RF) sputtering [8] was previously reported. In this context, hydrothermal method is one of the most popular and widely used methods to grow $\mathrm{ZnO}$ due to its relatively low-temperature process, environmentally friendly and lost cost [9]. In this paper, $\mathrm{ZnO}$ was grown by the hydrothermal method on $\mathrm{Si}$ wafer. It aims to understand the feasibility of this method for the $\mathrm{ZnO}$ growth on silicon ( $\mathrm{Si}$ ) wafer and to observe the effect on the morphology structure of the grown $\mathrm{ZnO}$.

\section{METHODOLOGY}

Starting materials: Table 1 summarized all the materials used in this research. They are used without further purification. 
Table 1: Starting materials for the $\mathrm{ZnO}$ growth

\begin{tabular}{|l|c|}
\hline \multicolumn{1}{|c|}{ Materials } & Provider \\
\hline $\begin{array}{l}\mathrm{Zinc} \text { acetate dehydrate } \\
\left(\mathrm{Zn}\left(\mathrm{CH}_{3} \mathrm{COO}\right)_{2} \cdot 2 \mathrm{H}_{2} \mathrm{O}\right)\end{array}$ & Merck \\
\hline $\begin{array}{l}\mathrm{Zinc} \text { nitrate hexahydrate } \\
\left(\mathrm{Zn}\left(\mathrm{NO}_{3}\right)_{2} \cdot 6 \mathrm{H}_{2} \mathrm{O}\right)\end{array}$ & Sigma Aldrich \\
\hline Hexamethylenetetramine $\left(\mathrm{C}_{6} \mathrm{H}_{12} \mathrm{~N}_{4}\right)$ & R \& M Chemical \\
\hline Sodium Hydroxide $(\mathrm{NaOH})$ & Sigma Aldrich \\
\hline Acetone & Merck \\
\hline 2-Propanol & Merck \\
\hline
\end{tabular}

Substrate preparation: n-type Si wafer $(1 \mathrm{~cm} \mathrm{x} 1 \mathrm{~cm})$ with a thickness of $\approx 0.525 \mathrm{~mm}$ was used as the substrate in this study. The substrate was immersed in deionized water and was cleaned in an ultrasonic bath for 10 minutes. Then, it was immersed in acetone and 2-propanol and was clean in an ultrasonic bath for another 10 minutes each. Finally, the substrate was dried on a hot plate at $70{ }^{\circ} \mathrm{C}$.

$\mathrm{ZnO}$ seed: $0.1 \mathrm{M}$ of $\left(\mathrm{Zn}\left(\mathrm{CH}_{3} \mathrm{COO}\right)_{2} \cdot 2 \mathrm{H}_{2} \mathrm{O}\right)$ was dissolved in $2.5 \mathrm{ml}$ of deionized water and $2.5 \mathrm{ml}$ of $\mathrm{NaOH}$. Then the mixture was stir for 30 mins using a magnetic stirrer at a temperature of $60{ }^{\circ} \mathrm{C}$. Then the solution was left for 24 hours in a dry box. After 24 hours, the prepared solution was spin-coated on the cleaned Si wafer for $30 \mathrm{~s}$ at a speed of 400 $\mathrm{rpm}$. Then the coated Si wafer was heated at $60{ }^{\circ} \mathrm{C}$ for $10 \mathrm{~min}$. Then, the Si wafer was re-coated with the similar method for a total of 3 times. Finally, the coated sampled was annealed at $300{ }^{\circ} \mathrm{C}$ for 1 hour.

$\mathrm{ZnO}$ growth: The $\mathrm{ZnO}$ growth was carried out in the zinc precursor solution via the hydrothermal method. $0.04 \mathrm{M}$ of $\mathrm{Zn}\left(\mathrm{NO}_{3}\right)_{2} \cdot 6 \mathrm{H}_{2} \mathrm{O}$ was added with $0.04 \mathrm{M}$ of $\mathrm{C}_{6} \mathrm{H}_{12} \mathrm{~N}_{4}$ and $20 \mathrm{ml}$ of deionized water. The prepared $\mathrm{Si}$ wafer with the $\mathrm{ZnO}$ seed layer was immersed in the precursor solutions in a beaker. Then, the beaker was sealed and heated to $95{ }^{\circ} \mathrm{C}$ and left for 30 minutes. After that, the prepared $\mathrm{Si}$ wafer was cleaned with distilled water for a few times and left to dry.

Characterization: The phase structure of the prepared sample was characterized by X-ray diffraction (Rigaku Miniflex II) with $\mathrm{CuK} \alpha$ radiation. To further verified the presence of the elements, energy dispersive X-ray (EDX) analysis was carried out (Oxford Instruments Ultim Max 40). Meanwhile, for the surface morphology structure of the sample was observed using a scanning electron microscope (SEM; JEOL JSM-6350LA).

In addition, the sample was tested for electrical validation caused by applied stress. The electrical response of a $\mathrm{ZnO}$ contained cantilever can suggests the sensitivity of the sample as an effective sensor. Higher sensitivity implies better sensing performance. The sensitivity can be detected by both applying a load or without a load. The latter is called open load mode. As such, the testing of the sample was performed in open load mode, i.e., no resistive load was attached. A dual-channel digital oscilloscope was used to detect the induced voltage from the sample. In order to create an inductive surface on the sample, aluminium thin sheet was used which collects the induced effect from the sample. The top and bottom of the sample were connected with the oscilloscope probes to detect the voltage variations. The collected voltage are presented in the following section.

\section{RESULTS AND DISCUSSION}

Figure 1 shows the XRD spectrum of the $\mathrm{ZnO}$ that was growth on the silicon wafer. From the figure, only two peaks are observed and these two peaks are corresponding to $\mathrm{ZnO}$ (PDF No. 65-2880) at $33.6^{\circ}$ and $70.5^{\circ}$ as well as Si (PDF No. 40-932) at $33.2^{\circ}$ and $68.6^{\circ}$. The full width at half maximum (FWHM) and the grain size of the $\mathrm{ZnO}(100)$ peak at $33.6^{\circ}$ were calculated as 1.3673 and $6.34 \mathrm{~nm}$, respectively. The crystallite size value is connected to the crystallinity process, where the nucleation rate involves in determining the crystal quality and orientations of $\mathrm{ZnO}$ particles [10]. In addition, Aneesh et al. reported that the crystallite size of the $\mathrm{ZnO}$ nanoparticle increases when the hydrothermal growth temperature increases [11]. From their work, they reported that the crystallite size was ranged from $7 \mathrm{~nm}$ to $16 \mathrm{~nm}$ for the temperature range of $100{ }^{\circ} \mathrm{C}$ to $200{ }^{\circ} \mathrm{C}$.

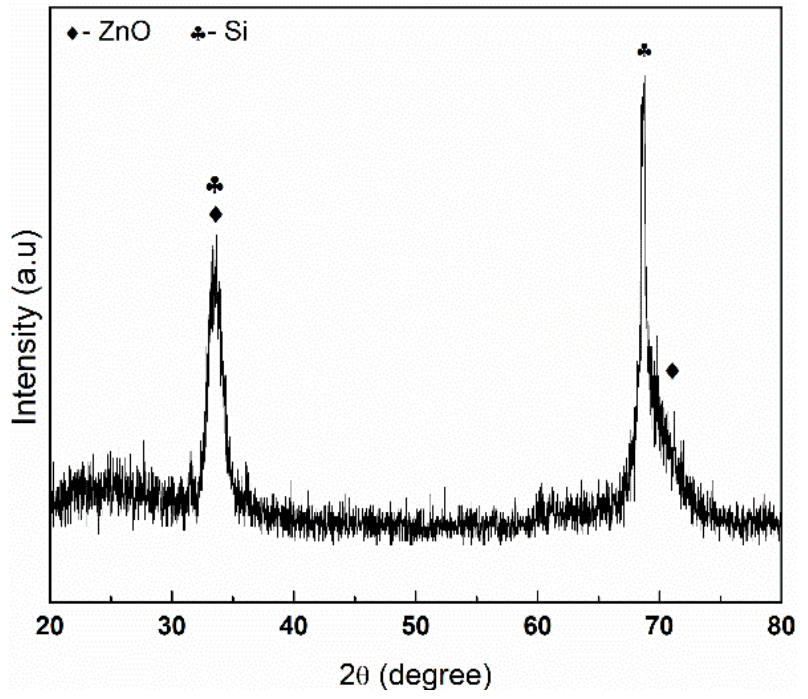

Figure 1: XRD spectrum of the growth $\mathrm{ZnO}$

Since these two peaks representing 2 elements, further characterization was carried out using EDX to verify the presence of elements. The EDX characterization of the sample was done at 505 times of magnification with $5 \mathrm{kV}$ of power. Through this characterization, the presence of $\mathrm{Zn}$ and $\mathrm{Si}$ in the sample is verified (Figure 2). The $\mathrm{ZnO}$ was proved to be grown homogenously on the $\mathrm{Si}$ substrate which can be deduced from colour distribution on the EDX image of the sample. Thus, it shows that the $\mathrm{ZnO}$ was grown successfully on the Si wafer via the hydrothermal method. 


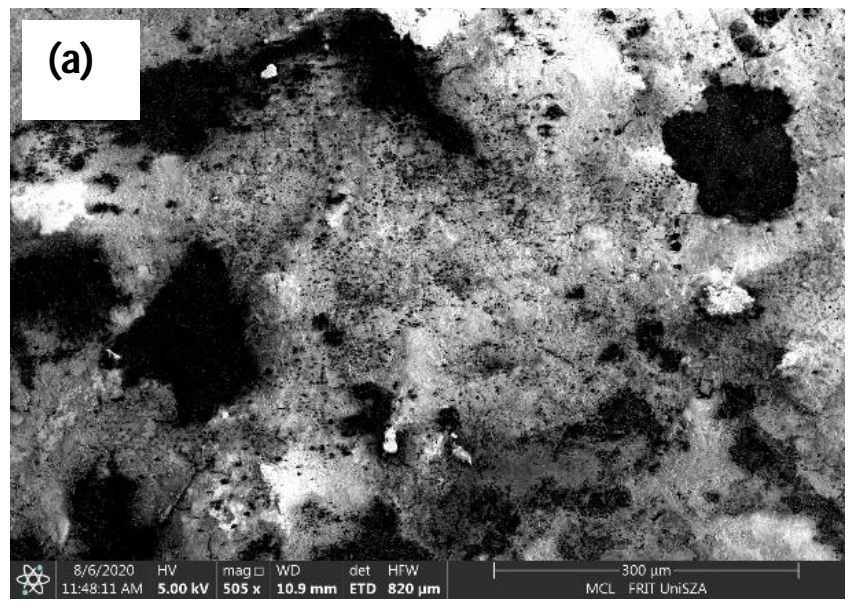

(b)

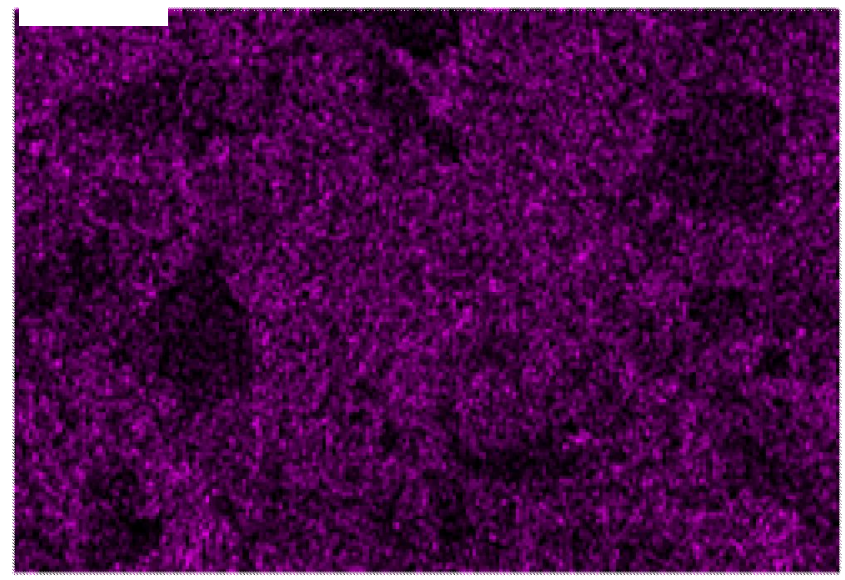

$250 \mu \mathrm{m}$

(c)

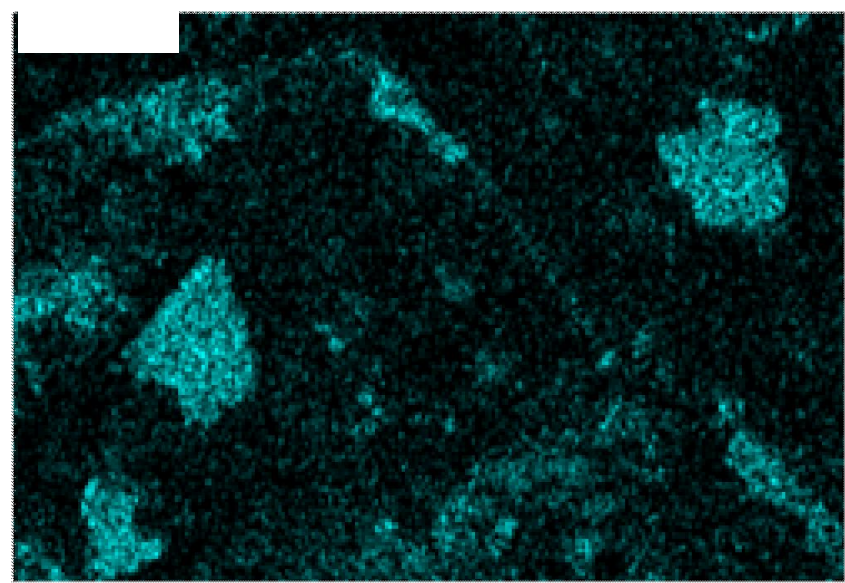

$250 \mu \mathrm{m}$

Figure 2: EDX image of the growth sample: (a) actual SEM image, (b) Zn element and (c) Si element

SEM characterization was carried out to study the surface structure of the $\mathrm{ZnO}$ growth on the $\mathrm{Si}$ wafer. The surface structure was examined at 5000 and 10000 times of magnification $(15 \mathrm{kV})$ as shown in Figure 3(a) and (b). Along with them, Figure 3(c) presents the layers formed due to the deposition. From the figures, interestingly, the $\mathrm{ZnO}$ structure was found to be a coral-like shape, which is full of asperities and sharp edges. The particle shape may occur due to a relatively low synthesis temperature and growth period. For instance, Fawcet and Poinern [12] reported that they found that the $\mathrm{ZnO}$ had hexagonal rods shape, flower-like shapes and fern-like shapes in a similar sample after 60 minutes of $\mathrm{ZnO}$ growth period on silicon chip wafers.
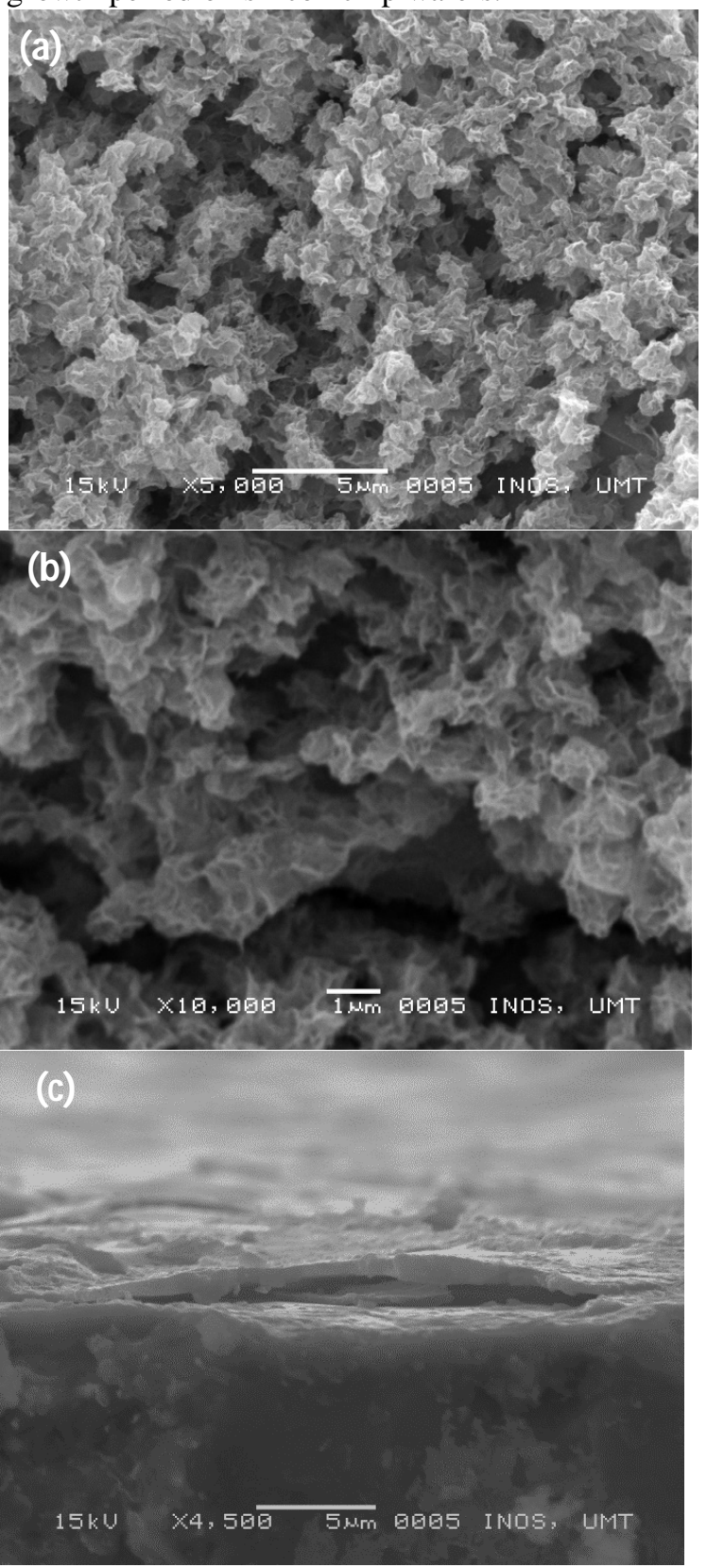

Figure 3: SEM image of the $\mathrm{ZnO}$ at (a) $5000 \mathrm{x}$ magnification (b) $10000 \mathrm{x}$ magnification and (c) $4500 \mathrm{x}$ magnification with layered exposure 
The fabricated sample was tested under random pressure to verify its electrical properties (in voltage) against applied random pressures. The pressure was produced by simple finger generated impact on the sample. The pressures were increased linearly in the consecutive tests. The observed produced voltages were $180 \mathrm{mV}$ to $240 \mathrm{mV}$ peak to peak from test 1 to test 4 . The output voltage implies the effectiveness of the fabricated sample despite the simplicity of the fabrication. In fact, the sample can be treated for comparison in the context of induced voltage [11]. Hence, this low profile cantilever can be used for ultra low frequency vibration sensor. The results are summarized in Table 2 .

Table 2: Induced voltages by the sample

\begin{tabular}{|c|c|}
\hline Test & Induced Voltage $\mathbf{~ m V ~ p p ~}$ \\
\hline Test 1 & 180 \\
\hline Test 2 & 196 \\
\hline Test 3 & 200 \\
\hline Test 4 & 240 \\
\hline
\end{tabular}

\section{CONCLUSION}

$\mathrm{ZnO}$ was growth on a $\mathrm{Si}$ wafer in this study through the hydrothermal method. From the XRD characterization, the presence of $\mathrm{ZnO}$ was confirmed. This output was further verified with the EDX characterization that confirms the presence of $\mathrm{Zn}$ element that is well distributed in the sample. The crystallite size was calculated to be $6.34 \mathrm{~nm}$. From the SEM analysis, the $\mathrm{ZnO}$ was found to has a coral-like shape, which is full of asperities and sharp edges. The sample was able to generate a voltage in the range of $180 \mathrm{mV}$ to $240 \mathrm{mV}$ peak to peak under random pressure.

\section{ACKNOWLEDGEMENT}

Authors would like to thank the Ministry of Higher Education Malaysia for the Fundamental Research Grant Scheme (FRGS) 59511 that used for this research. The authors would like to express gratitude to the Universiti Malaysia Terengganu (UMT) and Universiti Sultan Zainal Abidin (UNISZA) for providing the facilities to carry out this project.

\section{REFERENCES}

1. Borysiewicz M. A. ZnO as a functional material, a Review. Crystals. 2019, Vol. 9, pp. 505.

2. Elayaperumal M., Moodley M., Sinha Ray S., Panigrahi B., Krishnan R., Padhy N., et al. Zinc oxide epitaxial thin film deposited over carbon on various substrate by pulsed laser deposition technique. $J$ Nanosci Nanotechnol. 2010, Vol. 10, pp. 5602.

3. Özgür Ü., Alivov Y. I., Liu C., Teke A., Reshchikov M. A., Doğan S., et al. A comprehensive review of $\mathbf{Z n O}$ materials and devices. $J$ Appl Phys. 2005, Vol. 98, pp. 041301.

4. Cho S., Jung S.-H., Lee K.-H. Morphology-controlled growth of $\mathrm{ZnO}$ nanostructures using microwave irradiation: from basic to complex structures. $J$ Phys Chem C. 2008, Vol. 112, pp. 12769-76.

5. Yamada K., Tobisawa S. Fine crystals of zinc oxide formed by a conically converging shock $\square$ wave technique. J Appl Phys. 1989, Vol. 66, pp. 5309-14.

6. Kołodziejczak-Radzimska A., Jesionowski T. Zinc oxide-from synthesis to application: A review. Materials 2014, Vol. 7, pp. 2833-81.

7. Ismail A. S., Mamat M. H., Yusoff M. M., Malek M. F., Zoolfakar A. S., Mohamed R., et al. Structural, optical, and humidity sensing performance of $\mathrm{Pb}$-doped $\mathrm{ZnO}$ nanostructure prepared by sol-gel immersion method. International Journal of Advanced Trends in Computer Science and Engineering. 2019, Vol. 8, pp. 166-70.

8. Mohd Yusoff M. Z., Mohd Ridza P. N. I., Yahya M. S., Awal M. R. The etching of $\mathbf{Z n O / g l a s s ~ b y ~ h y d r o g e n ~}$ peroxide solution: surface morphological, structural, and optical properties. International Journal of Advanced Trends in Computer Science and Engineering. 2020, Vol. 9, pp. 3139-42.

9. Mayasari R. D., Mulyono A. E., Masmui, Swathatafrijiah W., Agustanhakri, Yuliani H., et al. Growth of $\mathbf{Z n O}$ nanorods on different substrates using hydrothermal method. Mal J Fund Appl Sci. 2020, Vol. 16, pp. 154-7.

10. Li W.-J., Shi E.-W., Zheng Y.-Q., Yin Z.-W. Hydrothermal preparation of nanometer $\mathrm{ZnO}$ powders. J Mater Sci. 2001, Vol. 20, pp. 1381-3.

11. Gaburro Z., Aneesh P. M., Cabrini S., Vanaja K. A., Jayaraj M. K. Synthesis of ZnO nanoparticles by hydrothermal method. Nanophotonic Materials IV. 2007, Vol. 6639, pp. 66390J.

12. Fawcett D., Poinern E. Low-temperature hydrothermal synthesis of zinc oxide structures on glass, silicon and indium tin oxide substrates. Int $J$ Sci. 2014, Vol. 3, pp. 63-9. 